\title{
A experiência audiovisual nos espaços educativos
}

\author{
Eloiza Gurgel Pires \\ Mestra em Educação pela Universidade de Brasília - UnB \\ e professora da Secretaria de Estado de Educação do Distrito Federal. \\ e-mail: eloizagurgel@uol.com.br
}

Resumo: O presente artigo propõe uma discussão sobre a experiência audiovisual no contexto dos espaços educativos, chamando atenção para a complexidade do momento em que vivemos. Localiza-se a Educação como importante mediação sociocultural nos processos de apropriação das linguagens e usos de diferentes suportes, especialmente o vídeo, para a expressão, criação e comunicação.

Palavras-chave: linguagem audiovisual, Educação, Comunicação, apropriações e representações midiáticas.
Abstract: The present article considers a quarrel on the audiovisual experience in the context of the educative spaces. When calling attention for the complexity the moment where we live, be situated it Education as important sociocultural mediation in the processes of appropriation of the languages and uses of different supports, especially the video, for the expression, creation and communication.

Keywords: audiovisual language, Education, Communication, midiáticas appropriations and representations.

Nosso sistema escolar construiu, durante um longo tempo, processos interacionais essencialmente baseados no relacionamento face a face e na palavra escrita. No entanto, o século XX ampliou, com as novas tecnologias, o leque de possibilidades de novas integrações direcionadas para diferentes objetivos e processos sociais, o que não poderia deixar de incidir sobre a Educação e outros setores da sociedade.

A relação dos jovens com as novas tecnologias representa, para MartínBarbero ${ }^{1}$, uma relação de cumplicidade cognitiva e expressiva, pois é nos sons, na velocidade, nas imagens e fragmentações que eles encontram seu ritmo e seu idioma. O autor chama atenção para o descentramento produzido pela televisão na cena doméstica, ressaltando o fato de que as crianças estão mais próximas do mundo dos adultos e que isso causa certa desordem nas seqüências de aprendizagem: as crianças agora sabem demais e vivem coisas que não são para sua idade.

Ao ser acusada de todos os males que cercam a vida dos jovens, a televisão desvela as transformações sociais da contemporaneidade a partir do desloca-

Recebido: 19/04/2006 Aprovado: 30/05/2007

1. MARTÍN-BARBERO Jesús. Novos regimes de visibilidade e descentramentos culturais. In: FILÉ, Walter. Batuques, fragmentações e fluxos. Rio de Janeiro: DP\&A, 2000. 
2. BENJAMIN, Walter. Obras escolhidas: magia e técnica, arte e política. São Paulo: Brasiliense, 1996.

3. DUBOIS, Philippe. Cinema, vídeo e Godard. São Paulo: Cosac Naify, 2004 mento das fronteiras entre razão e imaginação, saber e informação, natureza e artifício, arte e ciência, saber científico e senso comum. E, ao contrário do que muitos intelectuais afirmam, das representações e práticas sociais, em especial as juvenis, emerge uma nova subjetividade, abrindo espaço para um pensamento que não opõe escola e televisão, Educação e Comunicação.

Se, nos anos 1930, W. Benjamin ${ }^{2}$ associava as modificações do aparato perceptivo do transeunte no tráfego da grande urbe com a experiência do espectador de cinema, hoje, as transformações que atravessam o sensorium urbano são experienciadas no espaço doméstico, por meio da televisão e do computador. Diferentemente das culturas letradas, nos relatos fragmentados do vídeo, do cinema e das culturas eletrônicas audiovisuais, encontramos uma flexibilidade que permite a articulação de elementos de variados mundos culturais, coexistindo lado a lado com diferentes temporalidades.

Nesse sentido, a difusão do conhecimento é uma das questões mais importantes que a Comunicação propõe hoje para a Educação. No nosso sistema escolar, constata-se que não só existe o preconceito com relação à oralidade cultural, como também com relação à cultura audiovisual: uma atitude defensiva diante do desafio de reconhecer um novo ecossistema comunicativo, no qual emerge uma outra cultura, com novos modos de ler, ver, pensar e aprender.

\section{A LINGUAGEM VIDEOGRÁFICA}

Vivemos um momento histórico em que a mídia eletrônica deveria ser encarada - ao contrário do que muitos discursos apocalípticos pregam - como um fato da cultura, sendo o vídeo - ou uma forma vídeo de pensar toda e qualquer imagem ${ }^{3}-$ um veículo que, por excelência, expressaria a complexidade e as contradições do olhar contemporâneo.

$\mathrm{O}$ que chamamos de linguagem das formas audiovisuais não pode ser confundido com o sentido que se dá à linguagem verbal. A gramática do vídeo, assim como seu processo de articulação de sentido, é diferente da gramática das mensagens verbais. Não há uma tábua de valores ou uma gramática normativa que exponha o que se pode ou não fazer em vídeo, até porque se trata de um meio que possui um sistema híbrido, operando com diversos códigos significantes - do cinema, do teatro, da literatura, do rádio e, atualmente, da computação gráfica.

$\mathrm{O}$ vídeo surgiu num contexto histórico em que não se acreditava mais em uma gramática específica para os meios audiovisuais, pois os códigos videográficos não têm a mesma consistência e estabilidade das linguagens verbais, sendo impossível reduzi-los a um conjunto de regras esquemáticas.

No entanto, o vídeo também é um fenômeno de comunicação, que se dissemina de forma processual e não-hierárquica no tecido social, confundindo os papéis de produtores e consumidores, podendo resultar daí um processo de troca e de diálogo não muito comum em outros meios. Mas, para que haja 
comunicação, é preciso existir estruturas significantes, que sejam inteligíveis a emissores e receptores. Então, quando algo é transmitido pelo vídeo, haverá comunicação se as formas operadas e os modos de articulação forem comuns a todos os envolvidos nesse processo. Ainda que esse algo não possua uma lei, ou língua natural, contém uma linguagem ou sistema significante que garante sua inserção como canal de expressão numa sociedade.

O caráter híbrido do produto videográfico mostra-se mais rico na medida em que se torna aberto à intervenção do espectador, mesmo na manipulação física dos equipamentos e das mídias (CDs, DVDs, fitas etc). Surgindo, daí, a possibilidade instaurada por uma modalidade comunicacional interativa, do ato criador, a qual subverte a função da máquina - sua produtividade controlada -, reinventando seu uso e suas finalidades. A experiência criativa e de intervenção do espectador em um ambiente midiatizado redefine as formas de produção e, evidentemente, os modos de nos relacionarmos com a mídia e com o mundo ${ }^{4}$.

\section{PRODUÇÃO MIDIÁTICA NA ESCOLA}

Ao contrário do que imaginavam os teóricos da modernidade, o homo racionalis não está tão distante do homo esteticus. Isso traz profundas implicações no âmbito da Educação, que, nos dias atuais, passa por um processo de desconstrução das práticas tradicionais e construção de novas estratégias metodológicas.

Referindo-se ao processo de produção midiática na instituição escolar, Gonnet ${ }^{5}$ afirma que, quando o aluno vai à escola, já sabe o que esperam dele; então ele cria uma representação de seu lugar lá, que vai acompanhá-lo por toda a sua escolaridade. A produção de mídias representaria, nesse caso, uma nova capacidade dada aos jovens para se desenvolverem dentro de um espaço educativo, numa nova relação com eles mesmos, sendo mais importante a qualidade do projeto e não o suporte técnico.

Numa aventura com câmera e vídeo, os alunos podem descobrir não apenas a necessidade de elaborar roteiros, redigir um fio condutor, escolher lugares para filmagem, como também as funções necessárias à produção da obra (filmagem, montagem, sincronização etc.).

A respeito dessa descoberta, surgem algumas questões. O que suscitam essas ações? Como os jovens e os educadores se relacionam em uma experiência audiovisual nos espaços escolares? Como se descobrem, por meio de uma outra maneira de conceber a escola? Como traduzir um sentimento em imagens? Como se colocar diante da câmera? Deve-se fazer como na televisão ou tentar inventar um outro estilo? É certo, porém, que, com as regras de trabalho produtivo, na coletividade, os alunos também tomam conhecimento das responsabilidades que isso implica.

No contexto dos espaços educativos, redimensionar a autoridade do professor, considerando possíveis co-autorias, acarreta permanente negociação
4. Ver MACHADO, Arlindo. Máquina e imaginário. São Paulo: EDUSP, 2001.

5. GONNET, Jacques. Educação para as mídias. São Paulo: Loyola, 2004. 
6. BAKHTIN, Mikhail. Estética da criação verbal. São Paulo: Martins Fontes, 2003.

* Ver LAGO, Cláudia; LEÃO, Izabel. Revista Viração: um projeto social impresso. Comunicação \& Educação. São Paulo: CCA-ECA-USP/Paulinas, ano XII, n. 3, set./dez. 2007. (N.E.) entre os eus e as alteridades. Nesse sentido, o pensamento bakhtiniano propõe que o território interno de cada um não é soberano e que o outro ocupa um lugar de revelação, uma vez que a visibilidade do sujeito e sua própria consciência em relação a seu lugar espacial no mundo são determinadas pelo olhar do outro, pois cada um de nós se encontra na fronteira do mundo que vế ${ }^{6}$. Trata-se da necessidade estética do outro, o que implica um acontecimento ético. Nas relações sociais e nos espaços de interação criados pela linguagem audiovisual, as imagens do eu e do outro são vivenciadas de formas diferentes. Ao redimensionar sua autoridade, o professor recupera a relação lúdica com o instrumento técnico, diante do desafio de participar da aventura de construir com os alunos suas próprias imagens.

Por causa da importância social, cultural e econômica da mídia nas sociedades modernas, considera-se essencial uma educação que possibilite aos jovens uma visão mais ampla do universo midiático, pois os meios de comunicação fazem parte do nosso cotidiano, fornecendo-nos recursos simbólicos que usamos para conduzir e interpretar nossas relações e definir nossas identidades. Assim, a educação para as mídias - educar e aprender sobre a mídia - não deve ser confundida com ensinar através ou com a mídia, não se tratando, portanto, de tecnologia educacional ou mídia educativa.

No contexto da educação para as mídias, a produção não é um fim em si. Os jovens se apropriam da linguagem midiática para expressar suas idéias e seus sentimentos de forma criativa ou por meio da arte, usando a mídia também para a comunicação, sem, no entanto, reduzir isso a um treinamento técnico, sendo necessário o estabelecimento de uma relação dialógica entre professor e aluno e entre os próprios alunos numa permanente negociação. Nesse sentido, a linguagem audiovisual é vista não como um sistema fechado, mas processual, por meio do qual são construídas as representações e onde acontecem interações - espaço aberto a múltiplas leituras. O aluno é contextualizado como produtor e espectador de sua própria mensagem, visto como sujeito histórico, social e cultural, e não apenas como interlocutor; ele é criativo, transformador.

Os jovens criam representações de seu próprio grupo em suas histórias, como forma de definir identidades e negociar amizades numa produção midiática que, evidentemente, envolve trabalho coletivo*. A escola, inevitavelmente, torna-se um espaço para as negociações entre concepções de conhecimento e valores culturais.

No entanto, é preciso chamar atenção para o fato de que, apesar de vivermos em uma sociedade complexa, polifônica, com uma realidade constituída de diferentes olhares, em grande parte das instituições escolares, os jovens não são assumidos como atores sociais que elaboram representações sobre si mesmos e sobre os outros. Esses espaços educacionais, com toda a sua tradição positivista, atravessam um momento em que se faz necessário reconhecer os novos campos da experiência - reorganização dos saberes; hibridação da ciência; fluxo de informação; arte; trabalho e ócio; e novos meios de representação. 
A cultura midiática, diferente da cultura escolar, não segmenta aspectos racionais e emocionais - o sujeito sensível do sujeito inteligível. Para os educadores, torna-se um desafio a mudança de paradigmas e de estratégias metodológicas, pois, com as novas formas comunicativas e culturais, emergem novas subjetividades que desconfiguram o caráter formador da escola, que há muito tempo atua com uma racionalização disciplinadora separando os saberes - idades, o pensar do sentir, o trabalho do ócio.

A crise da razão moderna está desconstruindo as fronteiras rígidas entre as disciplinas, abrindo, assim, novos espaços sociais e culturais, mudando radicalmente nossos conceitos sobre o olhar, ler e conhecer. No entanto, percebe-se que os espaços educacionais são, ainda, a parte mais conservadora e desatualizada dentro de um contexto cultural; o que, para Milton José de Almeida ${ }^{7}$, minimiza seu poder político, com alta exposição manipulatória. Ao recuar das incertezas das mudanças sociais do mundo contemporâneo, a escola prefere estar à sombra de uma estabilidade aparentemente confortável.

Em uma experiência com câmera e vídeo em sala de aula, a expressão do aluno é fundamental. Até mesmo para que os conflitos e as contradições das instituições escolares sejam expressos, sem que as diferenças sejam tratadas com indiferença. A incorporação da cultura midiática no processo pedagógico reduz as resistências ao diálogo das instituições tradicionais, com a percepção de que discordâncias e conflitos são necessários ao processo de construção do conhecimento e elaboração da subjetividade.

Dar ao aluno a oportunidade de elaborar sua própria narrativa é, sobretudo, um ato político, que não deixa de ser poético, por se tratar, também, da exploração e da experimentação de uma linguagem multimidiatizada, que possibilita a re-invenção de uma escritura do mundo.

\section{APROPRIAÇÃO DA LINGUAGEM AUDIOVISUAL}

O conceito de apropriação, utilizado por Canclini ${ }^{8}$ ao se referir à interação entre elementos de variadas sociedades, sugerindo um diálogo entre as diferenças, é entendido por Chartier ${ }^{9}$ como formas diferenciadas de interpretação, intervenção criativa, apropriação cultural. Para Chartier, além da noção de apropriação, a noção de representação é fundamental dentro de um contexto sociocultural em que uma determinada realidade é construída, pensada, dada a ler, o que implica uma relação ambígua entre ausência e presença. No caso, a representação é a presentificação de um ausente, que é dado a ver segundo uma imagem, mental ou material, que se distancia do mimetismo puro e simples e trabalha com uma atribuição de sentido. Seria uma versão da realidade, não uma $a$-presentação, mas uma re-presentação.

Nesse sentido, todo conhecimento humano é uma construção simbólica, com seu modelo próprio de articulação, pois cada comunidade estabelece sua socialidade baseada nas próprias linguagens e leituras. Assim, as idéias e as re-
7. ALMEIDA, Milton José de. Imagens e sons: a nova cultura oral. São Paulo: Cortez, 2004.

8. CANCLINI, Nestor Garcia. Culturas híbridas: estratégias para entrar e sair da modernidade. São Paulo: EDUSP, 1998.

9. CHARTIER, Roger. A história cultural: entre práticas e representações. Lisboa: Difel, 1988. 
10. CERTEAU, Michel de. A invenção do cotidiano 1: artes de fazer. Petrópolis: Vozes, 2004

11. HALL, Stuart. A identidade cultural na pósmodernidade. Rio de Janeiro: DP\&A, 2005.

12. SOUZA, Solange Jobin e. Dialogismo e alteridade na utilização da imagem técnica em pesquisa acadêmica: questões éticas e metodológicas. In: FREITAS, Maria Tereza; SOUZA, Solange Jobin; KRAMER, Sônia (Orgs.). Ciências humanas e pesquisa: leituras de Mikhail Bakhtin. São Paulo: Cortez, 2003. p. 86.

13. MAFFESOLI, Michel. Notas sobre a pós-modernidade: o lugar faz o elo. Rio de Janeiro: Atlântica Editora, 2004.

14. BAKHTIN. op. cit., p. 31. comunicação \& educação • Ano XIII • Número 2 ・ maio/ago 2008

presentações figuram no cotidiano estruturando as percepções, as convivências sociais e os modos de estar no mundo, individual e coletivo.

Michel de Certeau ${ }^{10}$ chama-nos atenção para o fato de que as apropriações relacionam-se ao consumo. $\mathrm{O}$ autor remete ao ato de consumir o sentido de assimilar, dar um aspecto pessoal às representações e imagens que são disponibilizadas. Trata-se de um processo que não é individual, mas vivido socialmente. As relações sociais daí advindas definem variadas identificações que, segundo Hall ${ }^{11}$, constituem a própria incompletude do sujeito, que se reconhece (identifica) no olhar do outro e nas diferentes interpretações que faz do mundo e de si mesmo.

Nessa concepção, aquilo que, no sujeito, não pode ser visto por ele mesmo é mediado pelo olhar do outro, do seu ângulo de visão. Isto é, aquilo que ele não sabe sobre si mesmo se revela na relação com o outro. A construção da consciência que tem de si constitui o modo como ele compartilha o seu olhar com o olhar do outro. Dessa forma, cria-se uma linguagem que permite a comunicação no contexto das relações socioculturais.

Em uma experiência com as câmeras, o olhar das pessoas se expande, buscando novas formas de interlocução e de revelação. A experiência da mediação da imagem técnica proporciona uma outra visibilidade ao sujeito em relação a si mesmo, desencadeando, paradoxalmente, um sentimento de estranhamento no tocante àquilo que lhe é familiar: sua própria imagem. A relação entre o sujeito e as possibilidades oferecidas pelas câmeras é ambivalente, pois, se a sensação de perda de controle da própria imagem e do discurso representa uma ameaça, causando inibições, a relação com a própria imagem é, também, algo que seduz.

Com a consciência de sermos sujeitos efêmeros surge o desejo de permanência da nossa própria imagem, da nossa presença no mundo ${ }^{12}$. Quando o sujeito se coloca em frente às câmeras, ele sabe que sua imagem irá deslocarse, ganhando uma existência própria, sendo, posteriormente, retomada por outras pessoas em infinitas interpretações. Sabemos que, de modos diversos, este efeito é também alcançado na apropriação de outras linguagens, como, por exemplo, a escrita.

A sedução pela própria imagem é, também, aquilo que Maffesoli ${ }^{13}$ considerou como o perder-se no outro, ao se referir a um reencantamento do mundo favorecido pela tecnologia, que é acentuado pelo renascimento da imagem como um importante elemento do vínculo social - ao contrário de constituir um envolvimento narcísico. Quando o sujeito vê sua imagem nos espelhos comuns, ou nos espelhos eletrônicos das telas audiovisuais, essa imagem está situada fora e diante de si. Portanto, ele vê a um outro, relaciona-se com a dimensão alteritária de si mesmo.

Nos espelhos comuns, as imagens são invertidas, vê-se a simultaneidade dos gestos e há uma confusão entre aquele que está na imagem e o próprio sujeito. Para Bakhtin ${ }^{14}$, nossa situação diante do espelho é sempre um pouco falsa, pois, como não dispomos de um enfoque de nós mesmos de fora, recorremos a um outro possível e indefinido, que nos ajudará a encontrar uma posição ou uma forma para nós mesmos. Nossa relação com a imagem externa, segundo 
A experiência audiovisual nos espaços educativos • Eloiza Gurgel Pires

o autor, diz respeito, inicialmente, não à estética, mas ao seu eventual efeito sobre os outros. Avaliamo-nos não para nós mesmos, mas para os demais e por meio deles. Assim, a construção de diversas vozes sociais ou olhares costura a nossa imagem externa. Os outros, de que fala Bakhtin, aqueles com quem nos relacionamos, são constituintes do nosso imaginário, na representação que fazemos de nós mesmos.

Nas telas audiovisuais, a imagem é captada pela lente de uma câmera manipulada por alguém, que, através do seu olhar, redimensiona o tempo e o espaço vividos, reproduzindo essa imagem em espelhos eletrônicos que nos trazem informações novas, inusitadas e, às vezes, constrangedoras sobre nós mesmos. O que implica o reconhecimento de diferentes formas de escrever e representar a realidade e de expressar os imaginários.

Nos dias atuais, a maneira como nos apropriamos das imagens técnicas pode redefinir os modos de ver e de ser visto; a nossa própria forma de entender e lidar com os meios, ou de reinventá-los. De acordo com Martín-Barbero ${ }^{15}$, a escola adquire, nesse cenário, uma importância estratégica e decisiva no acesso às novas formas de conhecimento, no uso criativo e crítico dos meios de comunicação de massa e das tecnologias informatizadas. Contudo, é preciso lembrar que, no âmbito dos espaços educativos, à apropriação dos novos meios deve seguir-se uma nova práxis de comunicação, com a qual será possível transformar a leitura em escritura, potencializando, assim, a figura do educador, que de retransmissor de conteúdos converte-se em formulador de problemas, provocando interrogações e possibilitando o diálogo entre culturas e gerações.

A apropriação e a ressignificação dos códigos audiovisuais, e de qualquer outra linguagem, podem gerar expressões e manifestações de cultura em nossas sociedades. Dentro de um novo ecossistema comunicativo, a Educação se depara com o desafio de se apropriar da cultura midiática para criar novos espaços de interação, nos quais alunos e professores tornam-se co-autores na construção de conhecimentos, e de estéticas que implicam o reconhecimento do outro - num acontecimento ético.

\section{REFERÊNCIAS BIBLIOGRÁFICAS}

ALMEIDA, Milton José de. Imagens e sons: a nova cultura oral. São Paulo: Cortez, 2004.

BAKHTIN, Mikhail. Estética da criação verbal. São Paulo: Martins Fontes, 2003.

BENJAMIN, Walter. Obras escolhidas: magia e técnica, arte e política. São Paulo: Brasiliense, 1996.

CANCLINI, Nestor Garcia. Culturas híbridas: estratégias para entrar e sair da modernidade. São Paulo: EDUSP, 1998.

CERTEAU, Michel de. A invenção do cotidiano 1: artes de fazer. Petrópolis: Vozes, 2004.

15. MARTÍN-BARBERO, op. cit., p. 107. 
comunicação \& educação • Ano XIII • Número 2 - maio/ago 2008

CHARTIER, Roger. A história cultural: entre práticas e representações. Lisboa: Difel, 1988.

DUBOIS, Philippe. Cinema, vídeo e Godard. São Paulo: Cosac Naify, 2004.

GONNET, Jacques. Educação para as mídias. São Paulo: Loyola, 2004.

HALL, Stuart. A identidade cultural na pós-modernidade. Rio de Janeiro: DP\&A, 2005.

LAGO, Cláudia; LEÃO, Izabel. Revista Viração: um projeto social impresso. Comunicação \& Educação, São Paulo: CCA-ECA-USP/Paulinas, ano XII, n. 3, set./dez. 2007.

MACHADO, Arlindo. Máquina e imaginário. São Paulo: EDUSP, 2001.

MAFFESOLI, Michel. Notas sobre a pós-modernidade: o lugar faz o elo. Rio de Janeiro: Atlântica Editora, 2004.

MARTÍN-BARBERO, Jesús. Novos regimes de visibilidade e descentramentos culturais. In: FILÉ, Walter. Batuques, fragmentações e fluxos. Rio de Janeiro: DP\&A, 2000.

SOUZA, Solange Jobin e. Dialogismo e alteridade na utilização da imagem técnica em pesquisa acadêmica: questões éticas e metodológicas. In: FREITAS, Maria Tereza; SOUZA, Solange Jobin; KRAMER, Sônia (Orgs.). Ciências humanas e pesquisa: leituras de Mikhail Bakhtin. São Paulo: Cortez, 2003. 